\title{
Cannes Castoffs? The 62nd Edinburgh International Film Festival
}

\author{
'Everyone's entitled to their own \\ opinion, right?' \\ 'Wrong.' \\ 'He or she is entitled to their informed \\ opinion.'
}

Five minutes into Dreams With Sharp Teeth, Erik Nelson's documentary profile of author, screenwriter, and critic Harlan Ellison, my black little heart swelled as America's most curmudgeonly man of letters articulated just why I do what I do.

You see, like most critics, I'm a bit of a git; a smug know-it-all. I'm always right. And everyone who doesn't agree with me is wrong. Always.

If you don't believe me, watch this year's Edinburgh International Film Festival's opening night film, John Maybury's The Edge Of Love, then try and tell me that Keira Knightley and Sienna Miller are actresses and not Thunderbird puppets. Go on, try. They may be exquisitely sculpted, but be honest; Gerry Anderson has more to do with their acting technique than Stanislavski or Strasberg. And the only thing worse than Keira's singing as Vera, '40s nightclub chanteuse and childhood sweetheart of Dylan Thomas, is Miller's horrendous Oirish accent as Dylan's wife Caitlin; more Bengal than Ballymeena. Had it been made in the '70s by Ken Russell, Maybury's po-faced account of the tangled love life of the Welsh poet could've been a delirious camp classic in the style of Russell's other gloriously over-the-top tales of artists' lives The Music Lovers or Lisztomania. And in Russell's hands the scene where Miller and Knightley share a bath would have been worth the price of admission alone. Unfortunately it's not the '70s and that's 104 minutes of my life that John Maybury has stolen from me.

While The Edge Of Love may have been thinner and less tasty than Keira and Sienna's bathwater, at least it kicked off the 62nd Edinburgh International Film Festival, its 1st in its new June spot, with a bit of much-needed, old-fashioned
Hollywood glamour; both stars radiant and relaxed, bathed in the wash of paparazzi flashbulbs. According to EIFF Managing Director Ginnie Atkinson the move from August to June, away from Edinburgh's Festival season, is part of a 5-year plan for strategic growth that will put Edinburgh on the map as a film festival city. And moving it away from the more glamorous Venice Film Festival (end of August) and the Toronto Film Festival (start of September) should attract bigger films and stars. That was the plan anyway, although moving it closer to Cannes (mid-May) probably wasn't such a hot idea. And it would be churlish and mean-spirited of me to mention that The Edge Of Love's prestigious premiere at Edinburgh came only after it had been turned down for inclusion at Cannes.

The Edge Of Love wasn't the only handme-down at this year's festival, just its least satisfying. One of its most beautiful, Tarsem Singh's jaw-dropping The Fall, a film that's inexplicably languished on the shelf since its debut at the Toronto Film Festival 2 years ago, is as much about the nature of storytelling as it is about the story it tells. In 1920's Los Angeles an inquisitive young immigrant girl, Alexandria (Catinca Untaru), roams the hospital where she's recovering from a broken arm and bonds with Roy (Pushing Daisies Lee Pace), a bed-ridden movie stuntman who whiles away the time spinning her tales of the fantastical adventures and derring-do of a mismatched brotherhood of heroes on a quest for justice. But Roy's not a happy bunny and his tales take a dark turn when he asks Alexandria to do him a little favour and borrow some pills from the dispensary, just to help him sleep ...

Shot in over 20 countries, The Fall is a lush visual feast that relies on good oldfashioned talent and vision rather than CGI orcs to create its rich fantasy world, a world bound only by the imagination of its young protagonist. Fresh and genuine, Catinca Untaru's performance as

\section{Image from the film The Fall.}

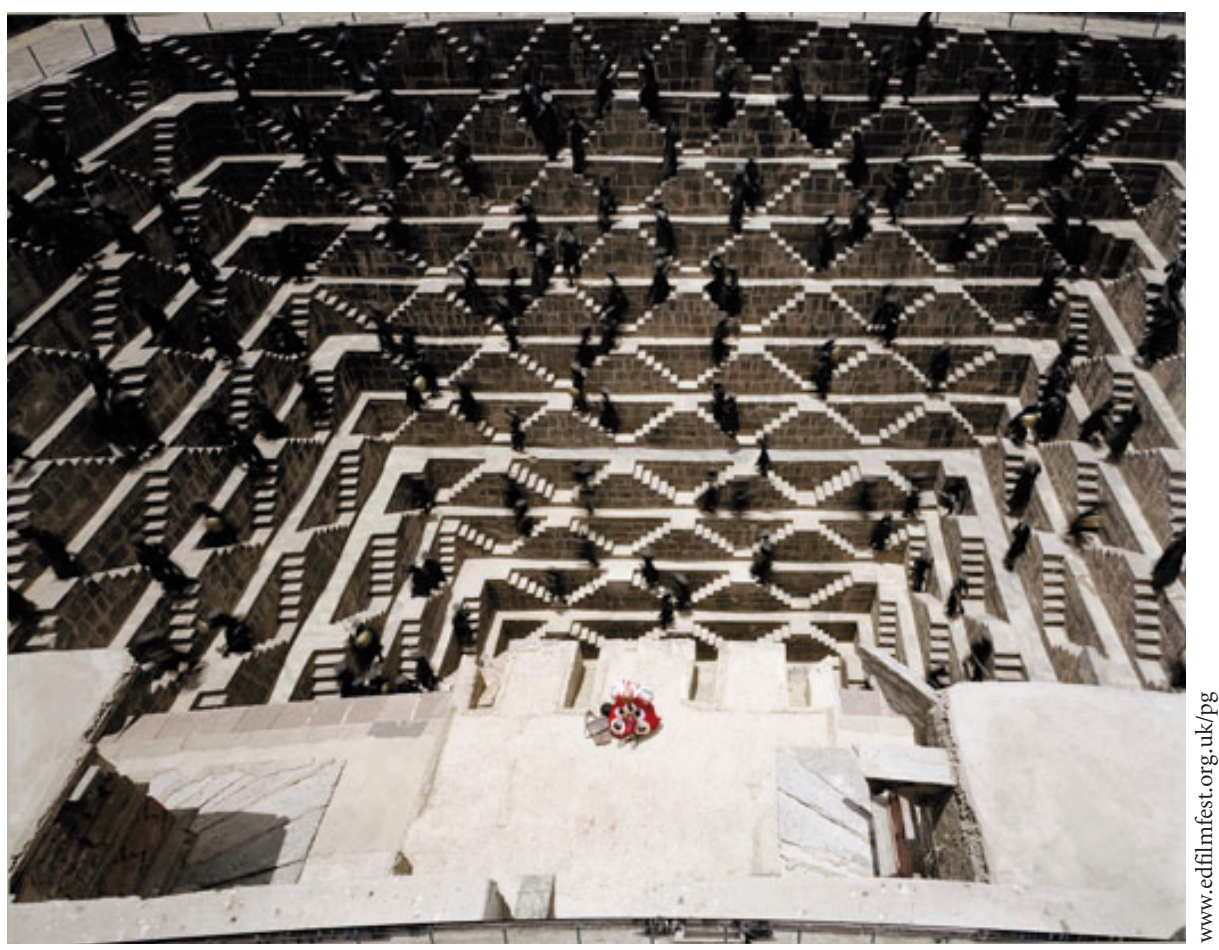


Alexandria is a delightful antidote to the precocious pre-teen divas Hollywood churns out; an engaging, exuberant presence upon whom the film rests. When American film critic Roger Ebert reviewed The Fall he wrote: 'You might want to see it for no other reason than because it exists. There will never be another like it.' Stunning and affecting, The Fall is a genuine original. They really don't make them like this anymore.

With few exceptions, Hannah McGill's second festival as artistic director was as underwhelming and safe as last year's. While her programme continued Edinburgh's tradition of showcasing firsttime filmmakers, there was a distinct lack of must-see films; nothing groundbreaking, nothing controversial. Pixar's WALL-E is critic-proof, I defy anyone not to like the tale of a lonely little robot looking for love, but it's no Finding Nemo. Thankfully, it's no Cars either. Thomas McCarthy's The Visitor was a less believable retread of his earlier film The Station Agent where a bunch of lonely oddballs bond and form a surrogate family. In The Station Agent the oddballs were a trainspotting dwarf, a motormouthed Chicano, and Patricia Clarkson who's always a bit mopey in everything. The Visitor is more of the same except it has illegal immigrant drummers, a mopey academic, and a distinct lack of dwarves.

There were no surprises in Germany's The Wave, which trotted out the old 'trendy teacher turns class into fascists to teach them the dangers of Nazism' chestnut. Unsurprisingly, a class of teenage Germans take to Fascism like ducks to water and it's all fun and games until the inevitable bitter end. Máncora was a sexy Peruvian road movie but if you've seen $Y$ tu mamá también you've already seen a sexier version. And I don't know what we did to deserve it but there was not one but two bland films from Wayne Wang (A Thousand Years Of Good Prayers and The Princess Of Nebraska).

As ever, the worst films on offer were
British. We had Full Monty-style plucky underdogs (Stone Of Destiny), Louis Theroux-style navel-gazing (A Complete History Of My Sexual Failures) and good old-fashioned British miserablism (Better Things and Summer). Somers Town was yet another attempt by Shane Meadows to prove himself the Midlands François Truffaut. Shot around London's St Pancras Eurostar terminal and funded by Eurostar, Meadows' film did make me want to climb on a Eurostar and get the hell out of the country just to avoid seeing any more Shane Meadows' films, so Eurostar probably consider it money well-spent. With a director, writer, and script chosen by MySpace users, words can't describe how appallingly bad the closing night film Faintheart actually is. It was the only film at this year's EIFF where the distribution company asked us to sign a press embargo. Twenty minutes into the film I wished l'd used the distributor's pen to poke out my own eyes instead.

Which isn't to say there were not good films at this year's Festival. Sweden's Let The Right One In gave us the year's most sympathetic anti-heroine, a pre-teen vampire, in a movie where the biggest monsters aren't the children of the night but the bullies who haunt 12-year old hero Oskar's school day. Red was a gripping slow-burner featuring Scots actor Brian Cox as a lonely widower whose simple quest for justice for his murdered dog escalates into a bloody small-town feud. Giving possibly his best performance since he chilled the blood as the original Dr Lecter in Michael Mann's Manhunter, Cox's small-town storekeeper is a wounded bear of a man, who simply won't be pushed around anymore.

Thumping Brazilian action thriller Elite Squad treated us to the flipside of City Of God's portrait of favela-life courtesy of the cops who police it while Mexico's Sleep Dealer presented a futuristic world Philip K Dick would have been proud of, where low-paid Mexicans hooked to computers still provide the US with cheap labour by crossing the border in virtual reality. Britain made a late entry into the torture-porn stakes with Donkey Punch and Mum And Dad. Directed by Olly Blackburn and named for the kind of apocryphal sex-act Loaded readers snigger about, Donkey Punch (Google it, Urban Dictionary's a good place to start) is repugnant but effective. A group of chav girls on an 18-30's holiday unwisely go for a boat trip with some charming lads and violence, rape, and murder ensue. While it delivered the requisite shocks, Donkey Punch's biggest problem was that I didn't really care about any of the characters. And I'm also quite childish so I kept trying to think of offensive sex-acts that could serve as the title for a sequel.

Steven Sheil's Mum And Dad was a gripping tale of domestic horror obviously inspired by Fred and Rose West that had me on the edge of my seat even when I wanted to be hiding behind it. When immigrant Heathrow toilet cleaner Olga misses her bus home she makes a big mistake when she accepts the offer of a bed for the night from chatty young colleague Birdie, particularly when she meets her new 'Mum' and 'Dad.' Shocking, nasty and genuinely upsetting, Mum And Dad gave me perverse hope for the future of the British film industry and also for the future of the Edinburgh Film Festival. If Hannah McGill can find a few more films like Mum And Dad and if, fingers crossed, Shane Meadows doesn't make any more films in the next 12 months, the 63rd Edinburgh International Film Festival may just be worth going to.

\section{David Watson}

DOI: 10.3399/bjgp08X319855 